\title{
Computational Fluid Dynamic Simulation of an Industrial Ethylene Decholride Thermal Reactor
}

\author{
Alireza Mohammadi, Nader Mokhtarian* \\ Department of Chemical Engineering, Shahreza Branch, Islamic Azad University, Shahreza, Iran \\ *Corresponding Author: Nader Mokhtarian, Department of Chemical Engineering, Shahreza Branch, \\ Islamic Azad University, Shahreza, Iran
}

\begin{abstract}
In the coming decades, polyvinyl chloride (PVC) is considered as the common plastics in petrochemical industries due to its high potential application. To make PVC's, monomers were produced firstly which is called vinyl chloride(VCM). This process is done in the ethylene dichloride thermal (EDC) cracking reactor within the temperature profile range of $680-758^{\circ} \mathrm{K}$ and the pressure drop of $25 * 105$ Pascal. The objectives of this comprehensive study is to simulate $2 D$ of thermal cracking reactor with FLUENT software and compare with an industrial reactor to obtain an optimum EDC conversion factor. Furthermore, the crucial parameters and their profound impact on the calculation of EDC conversion factor were taken into the consideration to spouse the importance of each parameter. Consequently, EDC conversion factor with the percentage of 52.69 has a good agreement with industrial data.
\end{abstract}

Keywords: Polyvinyl Chloride, Vinyl Chloride, Ethylene Dichloride Thermal, Conversion Factor, FLUENT Software

\section{INTRODUCTION}

Smart manufacturing (SM) is considered to those performances which are utilized and performed the intelligence of manufacturing provide sufficient production chains to obtain to the dramatic increase of current operational occasions. Manufacturing intelligence (MI) entails two different segments; the ubiquitous and affordable application of web-based technologies and pervasive administration of data gathering and its analysis, modelling and simulation procedures and subsequently the optimization processes to achieve a balance between components. To obtain the proper utilization of manufacturing intelligence in an industrial purpose, understanding of real-time circumstances, reasonable phenomena, pre- planned and accurate planning, and satisfying management of all steps of the manufacturing processing are urgently needed to address the current situation[1-5]. The appropriate designation and analytical simulation of thermal cracking reactors due to the complexity of chemical reactions among industrial procedures and the phenomenon of heating transfer in the furnace layers are the main concerns of petrochemical industries which they are effectively elaborated by numerous research activities to address the current industrial problems. In the coming decades, the administration of computational fluid dynamics (CFD) is widely popularized to facilitate the simulation of processing modulus like thermal cracking reactors and other equipment schematically to estimate the parameters such as velocity, and mass volume of transferred gas properly in the laboratory circumstances. Hence, these pre-planned analytical simulations which are principally based on the precious correlations enables engineers and industries to virtually eliminate the squander vast sums of money. Furthermore, due to the enhancement of computing sciences power in the modelling of dynamics fluid and processing simulations; in respect of the way, CFD modelling would enable engineers to simulate the compositional model entail both chemical and physical procedures with more detailed representatives of reactor geometry. Therefore, CFD modelling is considered as the comprehensive technique to appropriately deal with the complexities of boundary conditions and geometry characteristics. In addition, CFD modelling gives engineers the chance to modify the designation parametric values more flexible. Ethylene is one of the main building blocks in the petrochemical industry due to its high potential reactivity to make resins, fibres and plastics. Among numerous processes in petrochemical industries to make ethylene, ethane, naphtha, and propane 
thermal cracking procedures are the most common techniques which they are more affordable and preferable by petrochemical companies[5-9].

\subsection{Steady State Modelling And Steady State Optimization}

Shahrokhi and Nejati (2002) firstly proposed an extensive 1D steady state model of thermal cracking processes to distinguish the profile of gas temperatures alteration on the schematic reaction between molecules. Since then, Zhang, et., al. (2007) conducted an investigation into the 3D model of simulating the EDC reactors by the utilization of CFD methodologies. In this study, the profound impact of gas burners position in the firebox were taken into consideration regarding the performances of processing design goals[10-15].

\subsection{Dynamic Modelling and Dynamic Optimization}

Ghashghaee and Karimzadeh (2007) concentrated their insights into the dynamic modelling

of thermal cracking in the furnaces that were capable to estimate the unsteady-state crackers condition during start-up steps. Their proposed model consisted of four substantial mathematical model as convectional heat transfer model, firebox model, tube skin model, and tubular coil model. Thereby, selection of optimum Dynamic solution is illustrated as the best preferable technology to modify the current fluctuations.

\subsection{Tube Geometry and Meshing}

Mesh quality is one of the most substantial issue for the proper and best estimable CFD simulation and modelling procedures, i.e., a mesh with low quality needs the most robust CFD solver and subsequently accurate more computational processes to provide the best sustainable solutions. In the EDC procedures, the segments which are occupied with processing fluid in the furnace are called coils that are located in the horizontal position. The arrangement of coils in an industrial furnace are schematically depicted in figure 1 . As it is evident in figure 1, the produced heat is transferred by the coils in terms of radiation of convection models.

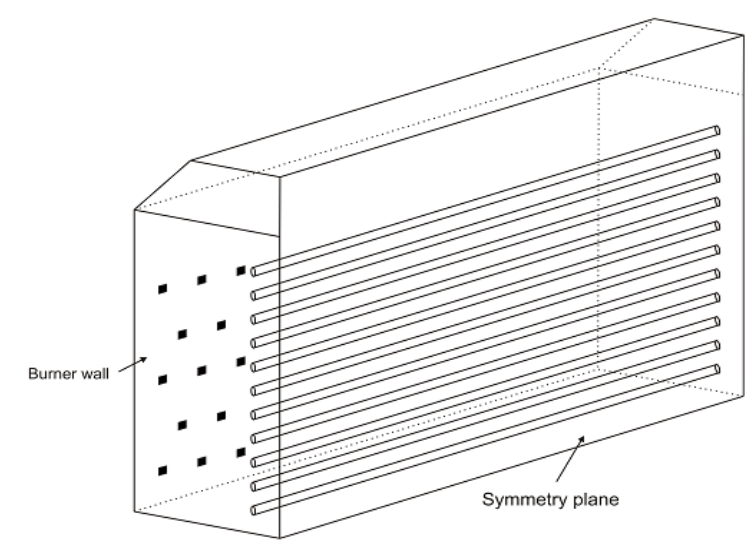

Figure1. Arrangement of Horizontal Coils in The Furnace

By using the equation 1, it is evident that from the EDC thermal cracking, vinyl chloride (VCM) and hydrochloric acid are produced. The major section of a thermal cracking unit is those section which cracking procedures are occurred in; in respect of the way, coils which are arranged in the furnace with a specific order. Thermal cracking furnaces are entailed radial and convectional areas. In addition, in convectional area used for the heating processes and evaporated the input feeds. The schematic of EDC thermal cracking furnace to change EDC to VCM is shown in figure 2.

$\mathrm{C}_{2} \mathrm{H}_{4} \mathrm{Cl}_{2} \rightarrow \mathrm{C}_{2} \mathrm{H}_{3} \mathrm{Cl}+\mathrm{HCl}$

Although, there are numerous studies are widely reported in literature to emphasize the considerable influence of CFD procedures in the thermal cracking reactors, in this comprehensive simulations, we try to propose an analytical EDC thermal cracking in an industrial furnace and qualify the suggested model to virtually eliminate the unnecessary expenditures. Moreover, the mathematical model would provide holistic by improving cracking reaction and increasing inside temperature of reactor, so that the conversion factor will be increased and subsequently the coke settling in the sidewall of the coil will be increased. 


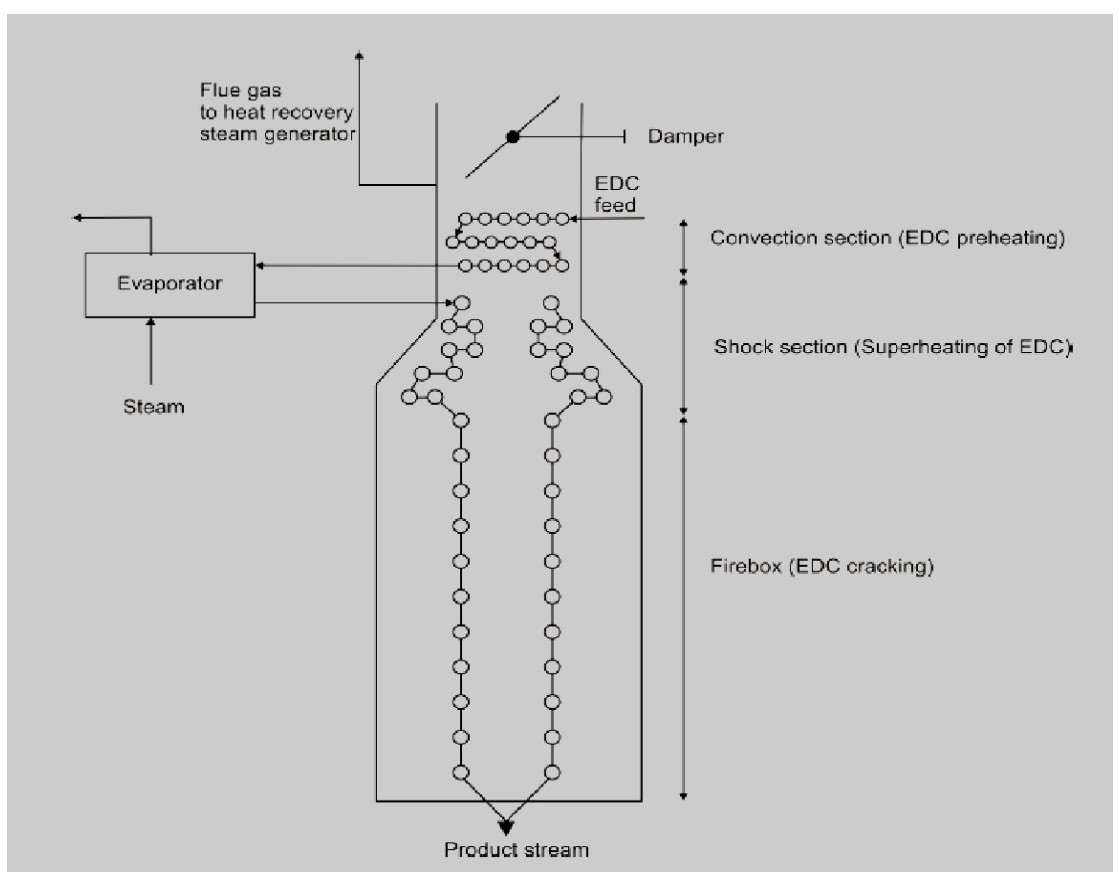

Figure2. Schematic of EDC thermal cracking furnace to change EDC to VCM

\section{Simulation Procedures}

\subsection{Governing Equations}

The assumptions which are used to calculate the following equations are described in figure 3.

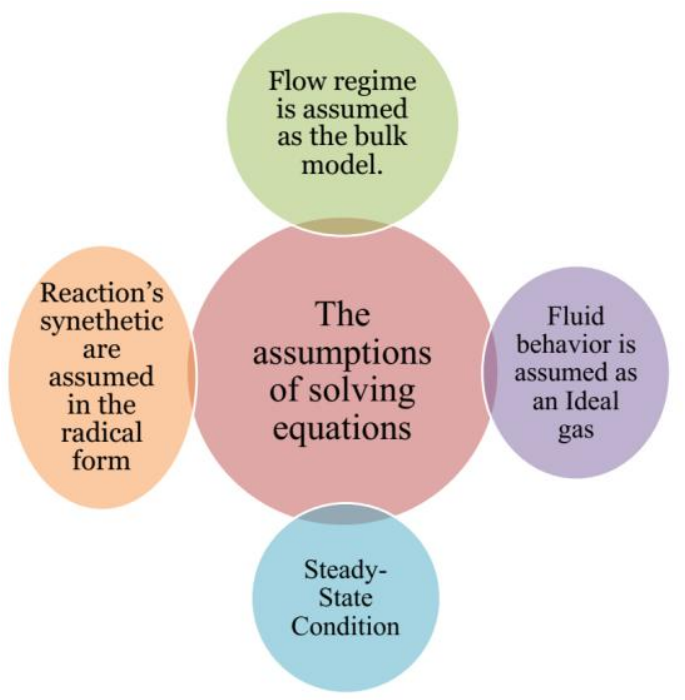

Figure3. Required Assumptions in the Correlations

The considered element in the length of coil which is used in mass balance equation is depicted in figure 4 . So the mass balance for all the participants in the equation is according to the equation 2.

$\frac{d F_{i}}{d Z}=\sum_{j=1}^{N R} \quad \gamma_{i j} \cdot r_{j}(z) \cdot M_{W i}(z) \cdot \frac{\pi \times D_{i}^{2}}{4}$

Where $\gamma_{i j}$ is the stoqumeteric factor for each component and $r_{j}$ is the number of each reaction which the reaction's component are described in table 1 and 2.

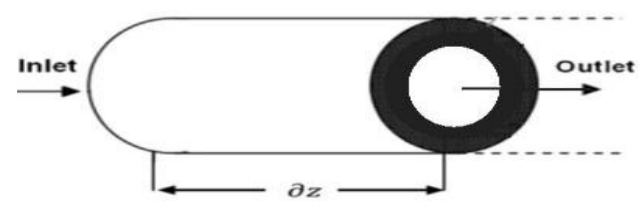

Figure4. Considered element in the length of coil 
Table1. Reaction's component (Molecule Components)

\begin{tabular}{|c|c|}
\hline 1,2-dichoroethane & EDC \\
\hline Vinyl-chloride & $\mathrm{VCM}$ \\
\hline hydrogen chloride & $\mathrm{HCl}$ \\
\hline Tri-chloro-methane & $\mathrm{CHCl} 3$ \\
\hline Tetra-chloro-methane & $\mathrm{CCl} 4$ \\
\hline Ethyl-chloride & $\mathrm{EC}$ \\
\hline 1,1 -dichloroethane & 1,1 \\
\hline $1,1,2$-trichlorothane & $1,1,2$ \\
\hline $1,1,1,2$, Tetrachloroethane & $1,1,1,2$ \\
\hline cis-/trans-di-chloro-ethyl & $\mathrm{Di}$ \\
\hline trichloroethylene & $\mathrm{Tri}$ \\
\hline $1-/ 2$-chloroprene & $\mathrm{CP}$ \\
\hline acetylene & $\mathrm{C}_{2} \mathrm{H}_{2}$ \\
\hline benzene & $\mathrm{C}_{6} \mathrm{H}_{6}$ \\
\hline $3,4-$ di-chloro-butane & $\mathrm{C}_{4} \mathrm{H}_{6} \mathrm{Cl}_{2}$ \\
\hline Soot/coke & $\mathrm{C}$ \\
\hline
\end{tabular}

Table2. Reaction's component (Radical Components)

\begin{tabular}{|c|c|}
\hline $\mathrm{Cl}$ & $\mathrm{R} 1$ \\
\hline $\mathrm{CH}_{2} \mathrm{Cl}_{-}-\mathrm{CH}_{2} * / \mathrm{CH}_{3}-\mathrm{CHCl}{ }^{*}$ & $\mathrm{R} 2$ \\
\hline $\mathrm{CH}_{2} \mathrm{Cl}-\mathrm{CHCl}$ & $\mathrm{R} 3$ \\
\hline $\mathrm{CHCl}{ }_{2}-\mathrm{CH}_{2}{ }^{*}$ & $\mathrm{R} 4$ \\
\hline $\mathrm{CHCl}=\mathrm{CH}^{*} / \mathrm{CH}_{2}=\mathrm{CCl}$ & $\mathrm{R} 5$ \\
\hline $\mathrm{CH}_{2} \mathrm{Cl}_{-}-\mathrm{CCl}_{2}{ }^{*} / \mathrm{CHCl}_{2}-\mathrm{CHCl}$ & $\mathrm{R} 6$ \\
\hline $\mathrm{CHCl}_{2}-\mathrm{CCl}_{2} * / \mathrm{CCl}_{3}-\mathrm{CHCl}$ & $\mathrm{R} 7$ \\
\hline $\mathrm{CCl}_{3} *$ & $\mathrm{R} 8$ \\
\hline
\end{tabular}

In the simulating processes with Fluent software, the equation for mass balance conditions is as equation 3;

$\frac{\partial\left(\rho y_{i}\right)}{\partial t}+\frac{\partial\left(\rho u_{i} y_{i}\right)}{\partial x_{i}}=-\frac{\partial J_{i}}{\partial x_{i}}+R_{i}+S_{i}$

Where $\rho$ is Density, $t$ is the period time, $u_{i}$ is the potential energy, $J_{i}$ is the diffusion term which demonstrated as the infiltration term and it doesn't utilized in the simulation processes, $s_{i}$ is the amount of heat at point $\mathrm{i}$, and $R_{i}=$ input heat to the reactor.

The overall energy balance equation is calculated by equation 4 .

$\sum_{i=1}^{N C} \quad \frac{F_{i}(z) \times C_{p m i}(z)}{M_{W i}(z)} \times \frac{d T(z)}{d Z}=\frac{\dot{Q}}{L}+\frac{\pi \times D_{i}^{2}}{4} \times \sum_{j=1}^{N R} \quad r_{j}(z) \times \Delta H_{r j}(z)$

Hence, the energy balance equation which is used in Fluent software is as equation 5;

$\frac{\partial}{\partial t}(\rho E)+\frac{\partial}{\partial x_{i}}\left(u_{i}(\rho E+p)\right)=\frac{\partial}{\partial x_{i}}\left(K_{e f f} \frac{\partial T}{\partial x_{i}}-\sum_{j} \quad h_{j} J_{j}+u_{j}\left(\tau_{i j}\right)_{e f f}\right)+S_{h}$

Where $T$ is the Temperature, $u_{i}$ is the input potential energy, $u_{j}$ is the output potential energy, $\tau_{i j}$ is the applied torque in both directions, $J_{j}$ is the output diffusion term, $s_{i}$ is the input thermal of chemical reactions, $S_{h}$ is the output thermal of chemical reactions, $K_{e f f}$ is the effective conductivity, and $\mathrm{E}$ is the total energy.

\subsection{Geometry of the Simulated Reactor and Mesh Property}

The geometry properties of simulated reactor are statistically demonstrated in table 3 and the schematic of one set of coil in the simulated furnace with more detail resolution is depicted in figure 5 .

Table3. Geometry of the Simulated Reactor

\begin{tabular}{|c|c|}
\hline Coil length & 95 meter \\
\hline Length of each branch & 13.5 meter \\
\hline Coil diameter & 0.134 meter \\
\hline Radius of the bend & 0.178 meter \\
\hline
\end{tabular}




\begin{tabular}{|c|c|}
\hline Length of the bend & 0.500 meter \\
\hline Number of bend & 9 \\
\hline Thickness of the wall & 0.800 meter \\
\hline
\end{tabular}

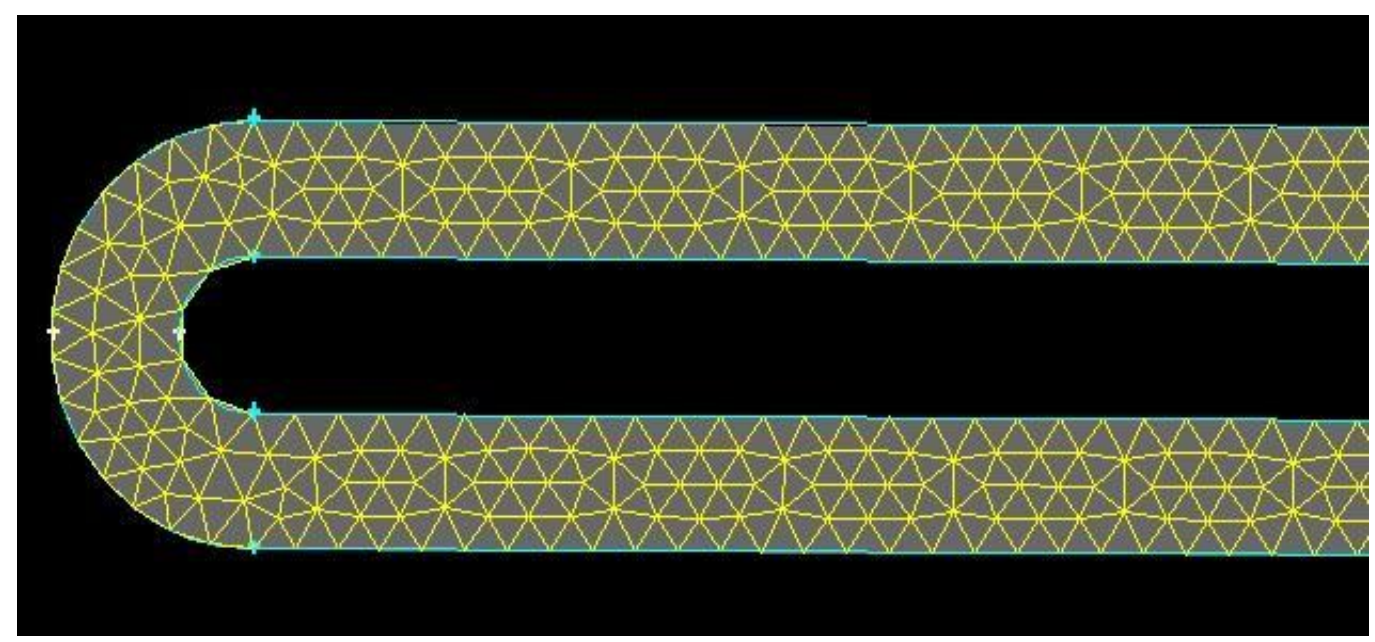

Figure5. One Set of Coil in the Simulated Furnace with More Detail Resolution

Furthermore, the properties of productive mesh are described in table 4.

Table4. Properties of Productive Mesh

\begin{tabular}{|c|c|}
\hline Mesh interval size & 0.03 \\
\hline Total elements & 165469 \\
\hline
\end{tabular}

Thermo- Physical Properties of Coil are clearly explained in table 5;

Table5. Thermo- Physical Properties of Coil

\begin{tabular}{|c|c|}
\hline$(\mathrm{K})$ Temperature & W/m.K)) Conductivity Factor \\
\hline 373 & 15.9 \\
\hline 573 & 19 \\
\hline 753 & 21.2 \\
\hline 973 & 25.7 \\
\hline $\left.\mathrm{kg} / \mathrm{m}^{3}\right)$ ) Density & 8470 \\
\hline $\mathrm{j} / \mathrm{kg} . \mathrm{k})$ ) Thermal Capacity & 444 \\
\hline
\end{tabular}

The overall schematic of EDC thermal cracking unit in the simulated furnace is plotted in figure 6.

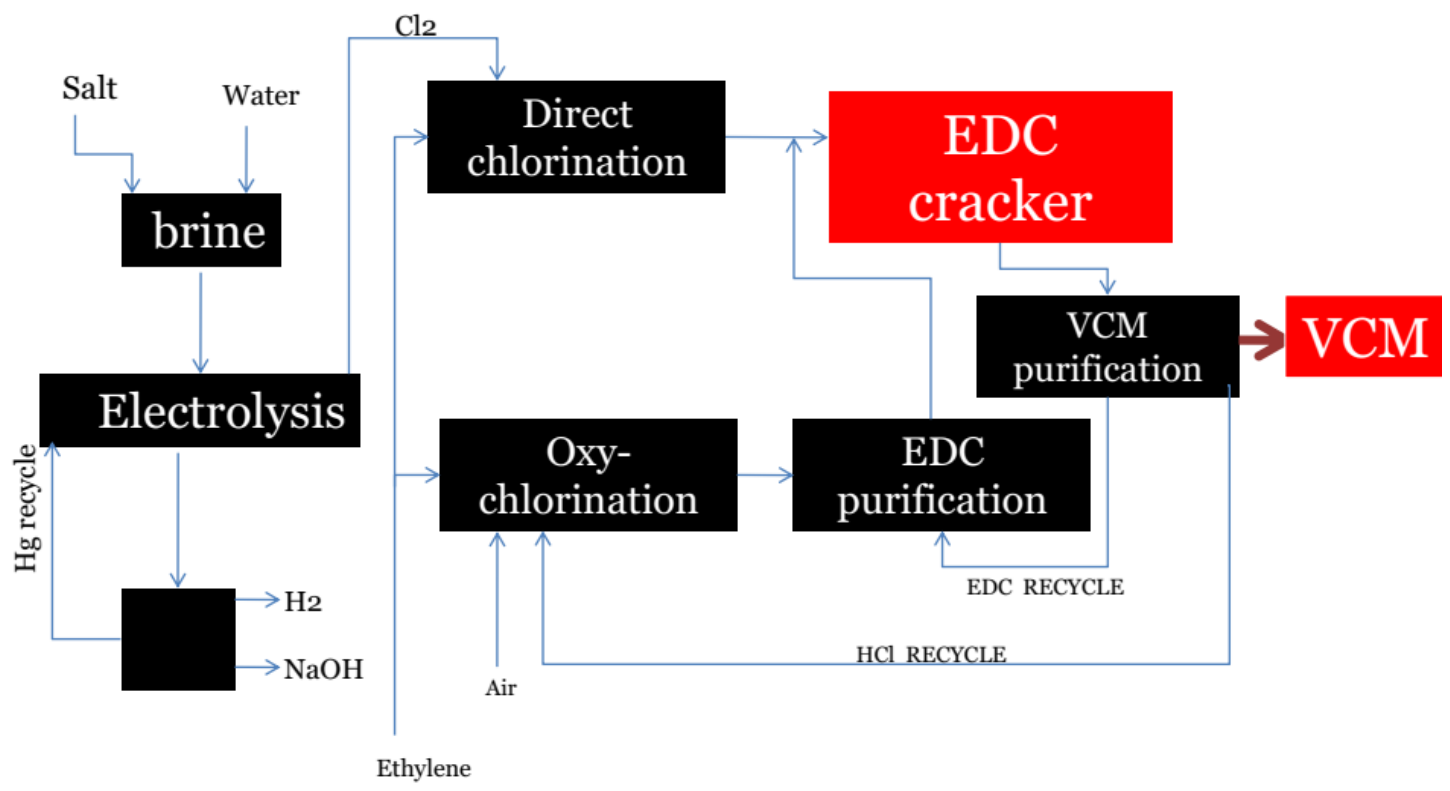

Figure6. Schematic of EDC Thermal Cracking Unit in The Simulated Furnace 


\subsection{FLUENT Software}

FLUENT Software is one the engineering software for simulating and modelling the operational processes and procedures in petrochemical industries to obtain the appropriate estimation of chemical reactions and analyse the considerable influence of each parameter. The software creates simulated computer models of structures, electronics, or machine components to simulate strength, toughness, elasticity, temperature distribution, electromagnetism, fluid flow, and other attributes.

\subsection{Inlet and Output Flow}

The fluid conditions of input and output flow is described in table 6 and 7;

Table6. Input fluid conditions

\begin{tabular}{|c|c|}
\hline Feed mass flow rate & $\mathrm{kg} / \mathrm{s} 6.086$ \\
\hline mass percentage of Input EDC & 0.9707 \\
\hline mass percentage of Input VCM & 0.0184 \\
\hline mass percentage of HCL input & 0.0109 \\
\hline
\end{tabular}

Table7. Applied boundary conditions for output flow in the software.

\begin{tabular}{|c|c|}
\hline location & Type of boundary condition \\
\hline Walls & Heat flux \\
\hline Input gas & Input mass rate \\
\hline Output flow rate & Output pressure \\
\hline
\end{tabular}

\subsection{Parameters of The Simulated Model}

The parameters which are used in this research are described statistically in table 8;

Table8. Parameters of the Simulated Model

\begin{tabular}{|c|c|}
\hline Parameter & Standard k-€ Model \\
\hline$C_{D}$ & 0.09 \\
\hline$C_{1}$ & 1.44 \\
\hline$C_{2}$ & 1.92 \\
\hline$\sigma_{k}$ & 1 \\
\hline$\sigma_{\varepsilon}$ & 1.3 \\
\hline
\end{tabular}

\section{RESULTS AND DISCUSSION}

\subsection{Selection of Appropriate Mesh}

To do this, in the simulation processes, five types of mesh are being taken into consideration and they are compared together. As can be seen in table 9, EDC conversion factor for the sets of mesh with the numbers of 172351 and 165649 are the most according to the results of simulation and it would be preferred for the experimental evaluation.

Table9. Selection of Appropriate Mesh

\begin{tabular}{|c|c|}
\hline Number of Mesh & EDC Conversion Factor \\
\hline 98452 & 47.05 \\
\hline 125893 & 49.1 \\
\hline 148216 & 50.8 \\
\hline 165649 & 52.69 \\
\hline 172351 & 52.69 \\
\hline Experimental Amount & 48.4 \\
\hline
\end{tabular}

\subsection{Fluid Temperature in the Coil Length}

Fluid temperature is one of the most considerable parameter which seriously affect the total procedures in the furnace. According to figure 7, the temperature alteration for the mixture at initial steps is drastically high, hence the temperature raised relatively $40 \mathrm{k}$. This temperature enhancement will continue up to about 45 meters of reactor length. Since then, the temperature is increased at the final length of the reactor; in respect of the way, the temperature rises so slowly at 105 meters in the final lengths. The reason for this is that, at the beginning of the reactor length, failure reactions have not yet begun, and much of the heat flux applied to the reactor is simply to increase the temperature of 
the gas mixture. In fact, the feed is preheated before entering the reactor. Although, it is necessary to prevent the initiation of defective reactions in the pre-heating zone, it is usually used in the first few meters of the applied heat exchanger to merge the mixture to the reaction temperature and basically there is no reaction in this area.

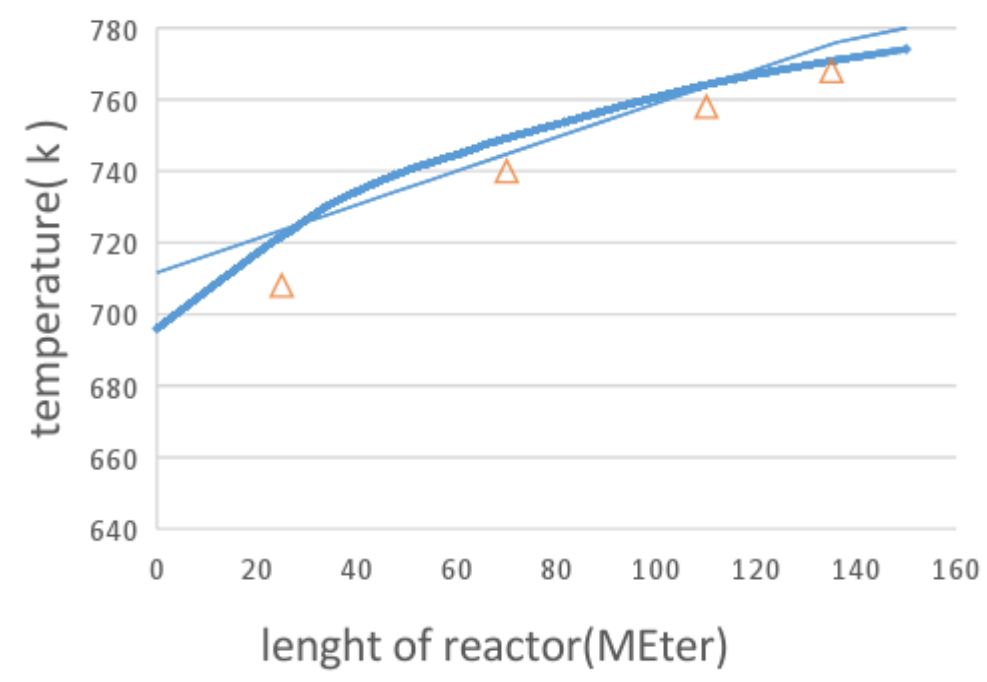

Figure7. Effect of Temperature on the Procedure

\subsection{EDC Mass Fraction Alteration}

Due to temperature soaring in the reactor, the conversion factor will be increased subsequently. Thereby, at the end length of the reactor, the conversion factor reaches the peak (it is approximately $53 \%$ ). In addition, EDC mass fraction in the inlet and at the outlet are 0.97 and 0.46 respectively. The plot of EDC mass fraction in the reactor length of is graphically shown in figure 8.

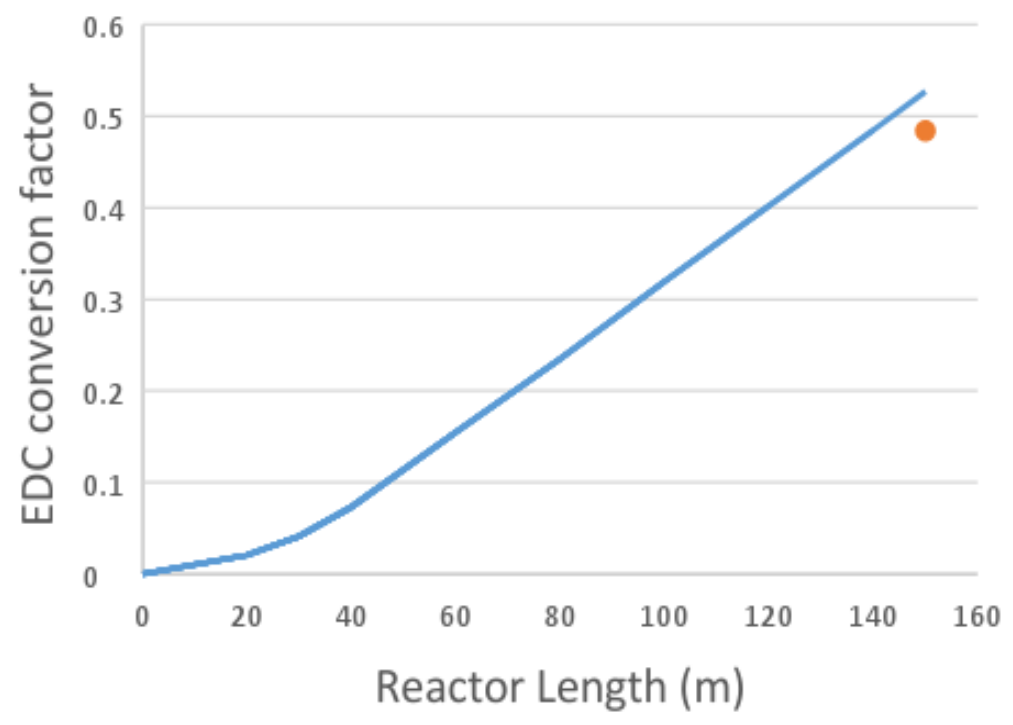

Figure8. EDC Mass Fraction Alteration

\subsection{VCM Mass Fraction Alteration}

At the beginning stages of the process, the applied heat in which is received from the furnace is used to increase the temperature of processing fluid is very low. Next, due to the progress of the procedure this amount will be increased significantly. Therefore, VCM mass fraction at the inlet and outlet are measured 0.018 and 0.23 respectively. It should be noted that a small amount of VCM at the inlet is regarding the result of feedback. This phenomenon is clearly depicted in figure 9. 


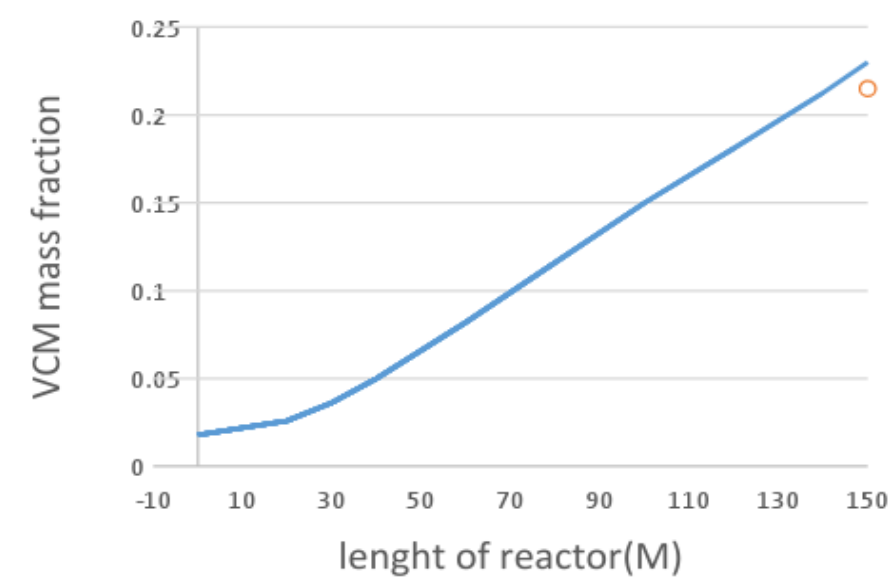

Figure9. VCM Mass Fraction Alteration

\subsection{Pressure Profile Alteration}

At the beginning of the process, the pressure drop in coils is very low which is be negligible. Since then, it seems a gradual increase with the reaction progress in the reactor and at the end of coils pressure drop will be increased drastically. Pressure profile alteration is shown in figure 10.

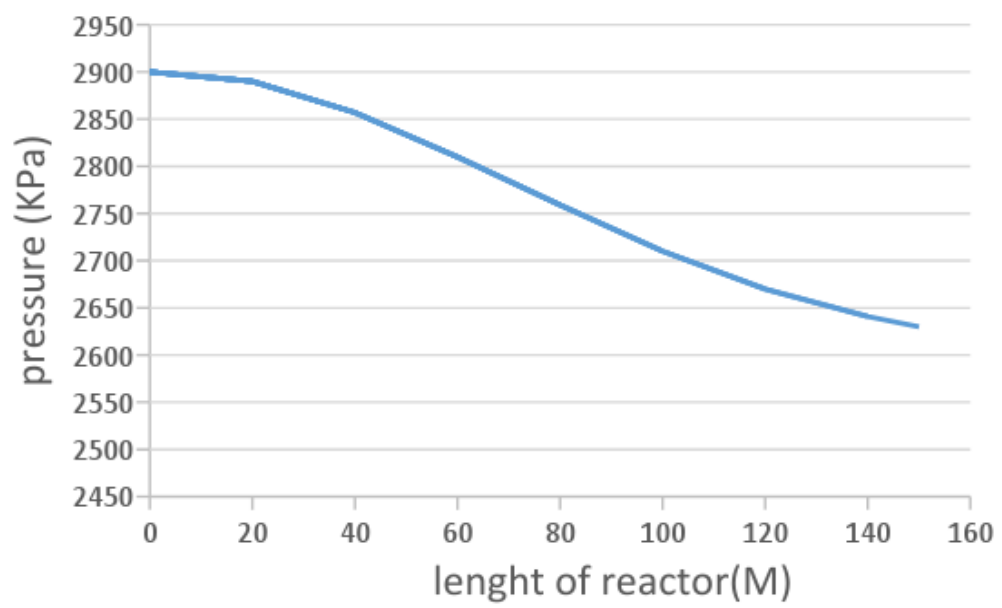

Figure10. Pressure Profile Alteration

Moreover, the EDC conversion factor is calculated for different equilibrium equations are explained in table 10.

Table10. EDC conversion factor for different equilibrium equations

\begin{tabular}{|c|c|}
\hline Gas Equilibrium Equations & EDC Conversion Factor \\
\hline Ideal Gas & 52.69 \\
\hline Peng Robinson & 51.42 \\
\hline Redlich Kwong & 50.78 \\
\hline Soave-Redlich Kwong & 50.45 \\
\hline Aungier-Redlich Kwong & 49.75 \\
\hline Industrial Experimental Data & 48.4 \\
\hline
\end{tabular}

\section{CONCLUSiON}

In this research FLUENT software is used for EDC thermal cracking procedures simulation in 2-D model. Due to the effective parameters which are fundamentally impact the cracking processes in the furnace, EDC conversion factor will be increased by increasing the temperature profile in the furnace. Moreover, Non-ideal assumption effects of processing fluids were also taken into consideration by administering the real gas. Therefore, the obtained conversion factor is seems more closer to industrial purposes. 


\section{REFERENCES}

[1] Davis, J., et al., Smart manufacturing. Annual review of chemical and biomolecular engineering, 2015.6 : p. 141-160.

[2] Jung, K., et al., Mapping strategic goals and operational performance metrics for smart manufacturing systems. Procedia Computer Science, 2015. 44: p. 184-193.

[3] Kang, H.S., et al., Smart manufacturing: Past research, present findings, and future directions. International Journal of Precision Engineering and Manufacturing-Green Technology, 2016. 3(1): p. 111128.

[4] Edgar, T.F. and E.N. Pistikopoulos, Smart manufacturing and energy systems. Computers \& Chemical Engineering, 2017.

[5] Hibino, H., et al., A Study on Lot-Size Dependence of Energy Consumption per Unit of Production Throughput Considering Buffer Capacity (Mini Special Issue on Smart Manufacturing). International journal of automation technology, 2017. 11(1): p. 46-55.

[6] Wang, G., et al., Prelude to rational scale-up of penicillin production: a scale-down study. Applied Microbiology and Biotechnology, 2014. 98(6): p. 2359-2369.

[7] Haringa, C., et al., Euler-Lagrange analysis towards representative down-scaling of a $22 \mathrm{~m} 3$ aerobic S. cerevisiae fermentation. Chemical Engineering Science, 2017. 170: p. 653-669.

[8] Haringa, C., H.J. Noorman, and R.F. Mudde, Lagrangian modeling of hydrodynamic-kinetic interactions in (bio)chemical reactors: Practical implementation and setup guidelines. Chemical Engineering Science, 2017. 157: p. 159-168.

[9] Haringa, C., et al., Computational fluid dynamics simulation of an industrial P. chrysogenum fermentation with a coupled 9-pool metabolic model: Towards rational scale-down and design optimization. Chemical Engineering Science, 2018. 175: p. 12-24.

[10] Shahrokhi, M. and A. Nejati, Optimal temperature control of a propane thermal cracking reactor. Industrial \& engineering chemistry research, 2002. 41(25): p. 6572-6578.

[11] Han, M.Y., et al., Energy band-gap engineering of graphene nanoribbons. Physical review letters, 2007. 98(20): p. 206805.

[12] Bassani, A., et al., Acid Gas to Syngas (AG2S $\left.{ }^{\mathrm{TM}}\right)$ technology applied to solid fuel gasification: Cutting H2S and CO2 emissions by improving syngas production. Applied Energy, 2016. 184: p. 1284-1291.

[13] El-Melih, A.M., et al., Experimental examination of syngas recovery from acid gases. Applied Energy, 2016. 164: p. 64-68.

[14] Pahlavan, M. and M.A. Fanaei, Modeling and simulation of Claus unit reaction furnace. Iranian Journal of Oil \& Gas Science and Technology, 2016. 5(1): p. 42-52.

[15] Mahmoudi, B., et al., CFD Simulation of Reactor Furnace of Sulfur Recovery Units by Considering Kinetics of Acid Gas (H 2 S and CO 2) Destruction. Applied Thermal Engineering, 2017.

[16] Bracco, S., et al., A dynamic optimization-based architecture for polygeneration microgrids with trigeneration, renewables, storage systems and electrical vehicles. Energy Conversion and Management, 2015. 96: p. 511-520. 


\section{AUTHORS' BIOGRAPHY}

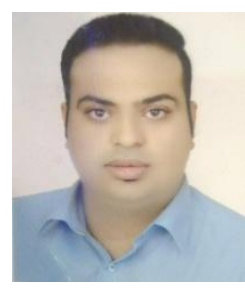

Alireza Mohammadi, Master degree of Chemistry Engineering at Islamic Azad University, Shahreza Branch. My current interests in Chemistry engineering sciences include a full-field study of Data Gathering and, Process Simulation. As a Chemistry Engineer, I systematically used my knowledge and experience to analyze the situation and then define, design and implement a method to reduce the environmental effects by reducing the unnecessary burning of gases at the flares.

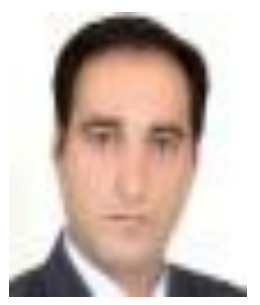

Dr. Nader Mokhtarian, is Associate Professor and M.SC. and doctoral student supervisor, and head of Department of Chemical Engineering at Islamic Azad University, Shahreza Branch, Iran, where he specializes in different substrate on performance of microbial fuel cell, Designation of advanced Reactors in petrochemical industries and, Joule Heating Effect on Electroosmotic Flow (Analytical Approach). He managed several research projects for the Department of Chemical Engineering at Islamic Azad University, Shahreza Branch. To date, Dr. Mokhtarian has published more than 30journal and conference papers.

Citation: Alireza Mohammadi \& Nader Mokhtarian, (2018). Computational Fluid Dynamic Simulation of an Industrial Ethylene Decholride Thermal Reactor, International Journal of Petroleum and Petrochemical Engineering (IJPPE), 4(1), pp.45-54, DOI: http://dx.doi.org/10.20431/2454-7980.0401006

Copyright: (C) 2018 Alireza Mohammadi \& Nader Mokhtarian, (2018). This is an open-access article distributed under the terms of the Creative Commons Attribution License, which permits unrestricted use, distribution, and reproduction in any medium, provided the original author and source are credited 